\section{Case Report of Refractory Psoriatic Arthritis Achieving Remission Using Nigella sativa (Black Seed Oil) Extract}

To the Editor:

Psoriatic arthritis (PsA) is one of the major extra skin manifestations of psoriasis and will develop in $20-30 \%$ of patients with psoriasis ${ }^{1}$. Alternative medicines, mainly herbal products, have been commonly used by patients for the treatment of psoriasis and there have been some studies into their efficacy, but most cases of PsA still require systemic therapy ${ }^{2}$.

Extract from Nigella sativa, also known as black seed oil, has been found to have antiproliferative, antiosteoporotic, antiinflammatory, and antidiabetic effects in many studies ${ }^{3}$. The major active ingredient, thymoquinone, has been demonstrated to have comparable results with topical hydrocortisone $2.5 \%$ when applied topically on carrageenan-induced paw edema and granuloma pouch on rats, manifested by a notable decrease in leukocyte count and tumor necrosis factor- $\alpha$ concentration in inflamed areas $^{4}$.

The use of $N$. sativa systemically for the treatment of PsA has not been investigated or reported in the literature. We describe the case of a patient with PsA refractory to both conventional and biologic therapy who achieved minimal disease activity state when he took oral black seed oil treatment on his own.

The patient is a 56-year-old man who was diagnosed with PsA at the age of 31 with polyarthritis, axial disease, and severe skin plaque psoriasis. $\mathrm{He}$ had no uveitis and no gastrointestinal disease. His main persistent joint complaints were bilateral knee synovitis, for which he received multiple intraarticular steroid injections and bilateral synovectomies to no avail. He was initially treated with indomethacin $150 \mathrm{mg}$ per day, along with methotrexate $25 \mathrm{mg}$ weekly with no improvement, followed by celecoxib $400 \mathrm{mg}$ per day, after which he was prescribed etanercept (ETN) $50 \mathrm{mg}$ weekly in 2003. He continued ETN until 2011, when he chose to stop. Unfortunately, during all these years, the patient sustained chronic deformities in his hands bilaterally in the distal interphalangeal joints. ETN was resumed later in 2016 with partial response until April 2019, when the patient decided to switch to alternative medicine. He started by applying $N$. sativa (black seed) cold-pressed $100 \%$ oil marketed over the counter topically to the inguinal area where he had severe skin plaques. He noticed marked improvement - the skin cleared within a week of treatment. In light of these results, he decided to take orally around 2 teaspoons $(10 \mathrm{~g})$ of this extract containing $400 \mathrm{mg}$ of thymoquinone. After only 3 days of oral treatment, he reported marked improvement in his arthralgias and complete resolution of his knee pain. This was documented when he presented for followup at our clinic 3 months later. On examination, the patient had no active arthritis except for a mildly swollen right knee. He also had improved range of motion of bilateral hands and knees. Skin examination did not reveal any active psoriatic lesion [Psoriasis Area and Severity Index $(\mathrm{PASI})=0$ ]. The patient's Disease Activity Index for Psoriatic Arthritis score while taking ETN was 25 , indicating moderate disease activity. This score went down to 4 , indicating remission, only 3 months after starting the oral $N$. sativa extract. He also fit the classification criteria of minimal disease activity described by Coates, et $a l^{5}$.
This case serves as an eye-opener for the use of alternative medicine and exploration of potential novel therapeutic effects of the active ingredient of such plants. Black seed oil extract's inhibitory effect on skin keratinocytes inflammation in albino rats with imiquimod-induced psoriasis-like lesions was demonstrated by Okasha, et $a l^{6}$. This was also described previously by Dwarampudi, et al using ethanolic extract of black seeds on a mouse tails model ${ }^{7}$. Another case series using a natural preparation including black seed extract showed treatment success defined by PASI reduction of at least $75 \%$ in 10 out of the 12 patients included 8 .

Further investigations and structured randomized control trials are needed for better understanding of the effect of $N$. sativa oil, and its active ingredient in the treatment of inflammatory disorders such as PsA.

MOHAMAD ALI RIDA® , MD; DAFNA D. GLADMAN『, MD, FRCPC, Psoriatic Arthritis Program, Centre for Prognosis Studies in The Rheumatic Diseases, and Krembil Research Institute, Toronto Western Hospital, Toronto, Ontario, Canada. Address correspondence to Dr. D.D. Gladman, Toronto Western Hospital, 399 Bathurst St. 1E-410B, Toronto, Ontario M5T 2S8, Canada. E-mail: dafna.gladman@utoronto.ca

\section{REFERENCES}

1. Ocampo DV, Gladman D. Psoriatic arthritis [version 1; peer review: 2 approved]. F1000 Research 2019;8(F1000 Faculty Rev):1665.

2. Harsha MR, Baidyanath M, Chaithra CS, Vivekananda R. Anti-proliferative effects of an herbal formulated cream on human keratinocytes and its implication for psoriasis treatment. Int $\mathrm{J}$ Bioassays 2016;5:4686-90.

3. Gholamnezhad Z, Havakhah S, Boskabady MH. Preclinical and clinical effects of Nigella sativa and its constituent, thymoquinone: a review. J Ethnopharmacol 2016:190:372-86.

4. Dwita LP, Yati K, Gantini SN. The anti-inflammatory activity of Nigella sativa balm sticks. Sci Pharm 2019;87:3.

5. Coates LC, Fransen J, Helliwell PS. Defining minimal disease activity in psoriatic arthritis: a proposed objective target for treatment. Ann Rheum Dis 2010;69:48-53.

6. Okasha EF, Bayomy NA, Abdelaziz EZ. Effect of topical application of black seed oil on imiquimod-induced psoriasis-like lesions in the thin skin of adult male albino rats. Anat Rec 2018;301:166-74.

7. Dwarampudi LP, Palaniswamy D, Nithyanantham M, Raghu PS. Antipsoriatic activity and cytotoxicity of ethanolic extract of Nigella sativa seeds. Pharmacogn Mag 2012;8:268-72.

8. Michalsen A, Eddin O, Salama A. A case series of the effects of a novel composition of a traditional natural preparation for the treatment of psoriasis. J Tradit Complement Med 2016;6:395-8.

First Release June 1 2020; J Rheumatol 2020;47:8; doi:10.3899/jrheum.191292 